Meta

Journal des traducteurs

Translators' Journal

\title{
Investigating the Translation Process
}

\section{Wolfgang Lörscher}

Volume 37, numéro 3, septembre 1992

URI : https://id.erudit.org/iderudit/003517ar

DOI : https://doi.org/10.7202/003517ar

Aller au sommaire du numéro

\section{Éditeur(s)}

Les Presses de l'Université de Montréal

ISSN

0026-0452 (imprimé)

1492-1421 (numérique)

Découvrir la revue

Citer cet article

Lörscher, W. (1992). Investigating the Translation Process. Meta, 37(3), 426-439. https://doi.org/10.7202/003517ar

\section{Résumé de l'article}

L'auteur décrit la méthodologie et les stratégies d'analyse développées dans le cadre d'un projet de recherche ayant pour objectif l'analyse psycholinguistique de la performance traductionnelle à partir d'un corpus de traductions orales (allemand-anglais et vice versa) en vue de reconstruire les stratégies qui sous-tendent la traduction. Il présente ensuite les éléments propres aux stratégies de traduction ainsi que leurs structures de base. Il donne enfin des exemples d'application de son modèle d'analyse et termine par une analyse quantitative des stratégies de traduction à partir de la langue maternelle et vers celle-ci. 


\title{
INVESTIGATING THE TRANSLATION PROCESS
}

\author{
WOLFGANG LÖRSCHER \\ Institute of English and American Philology \\ University of Dortmund, Dortmund, Germany
}

\begin{abstract}
Résumé
L'auteur décrit la méthodologie et les stratégies d'analyse développées dans le cadre d'un projet de recherche ayant pour objectif l'analyse psycholinguistique de la performance traductionnelle à partir d'un corpus de traductions orales (allemand-anglais et vice versa) en vue de reconstruire les stratégies qui sous-tendent la traduction. Il présente ensuite les éléments propres aux stratégies de traduction ainsi que leurs structures de base. Il donne enfin des exemples d'application de son modèle d'analyse et termine par une analyse quantitative des stratégies de traduction à partir de la langue maternelle et vers celle-ci.
\end{abstract}

\section{PRELIMINARY REMARKS}

Until very recently, translation theory has been primarily concerned with two phenomena (cf. Lörscher 1991): with translation as a product and with translation competence:

- Translation as a product, i.e. a written text in a target-language (TL) as the result of a translation process, has traditionally been described and analyzed by a comparison with the respective source-language (SL) text. The relation between the SL text and the TL text has been dealt with in a large number of different and highly theoretical models of equivalence. By and large, these models have been prescriptive rather than descriptive and of very limited use to the practical translator.

- Translation theory was mainly competence-oriented and focussed on (professional) translators' internalized knowledge. The models of translation were theoretical and speculative rather than empirical and concentrated on idealizations rather than on actually occurring data.

As a consequence of translation theory being product - and competence-oriented, hardly any attention has been given to the process by which a translation is produced, and to translators' actual performance. This narrowing of the object and of the dimensions in which it is investigated have only recently been realized to be a deficit. As a result, a new, process-oriented, performance-analytical discipline within translation studies has developed (cf. Gerloff 1988; Jääskeläinen 1990; Krings 1986; Lörscher 1991; Séguinot 1989; Tirkkonen-Condit 1991).

The empirical investigation of the translation process seems to be especially important for three reasons:

1. As far as the psycholinguistic investigation of translation is concerned, it can be expected that only on the basis of empirical studies of translation performance using a process-analytical approach can hypotheses on what goes on in the translator's head be formed. Thus, light could be shed on translation as a psychological process which is still largely unknown and uninvestigated. 
2. As far as psycholinguistic investigation in general is concerned, it can be expected that empirical studies of translation performance will yield general insights into language processing, about aspects of the mental processes of speech reception and speech production and about the mental strategies employed by the language user.

3. As far as the teaching of translation is concerned, it should be possible to make use of knowledge of the translation process for teaching translation. If certain translation strategies turn out to be successful, it might be worth considering teaching these strategies in one way or other.

My own research, and thus the considerations made in this paper, can be located within this newly established field. They are based on a research project which I have been carrying out since 1983 . The aim of this project is to analyze psycholinguistically translation performance as contained in a corpus of orally produced translations from German into English and vice versa. This is done in order to reconstruct translation strategies. These underlie translation performance, operate within the translation process, and are thus not open to direct inspection. In the first stage of the project, translation processes of advanced foreign language learners were investigated. The results yielded are contained in my monograph Translation Performance, Translation Process, and Translation Strategies. A Psycholinguistic Investigation, Tübingen 1991. The second stage of the project, in which professional translators' and, later on, bilingual children's translation processes are analyzed, is in progress (Lörscher in preparation).

\section{METHODOLOGY}

As concerns the methodology employed in researching the object of investigation, a distinction can be made between methods and procedures for the elicitation of data and those for the analysis and evaluation of data.

\section{Methods for Data Elicitation}

Among the methods for the elicitation of data, the introspective procedure of thinking-aloud (Ericsson/Simon 1984) is of decisive importance. The following seven arguments capture what to me seem to be the main points concerning introspective methods in general, and thinking-aloud in particular, as a means for eliciting information about translation processes in my investigation (Lörscher 1991: 48ff.):

I. It is generally accepted that subjects can only report what is in their focus of attention. It is only information stored in the short-term memory which can be externalized, and which, by definition, is in the individual's focus of attention. There is no way of getting information about mental processes which are not given cognitive attention by means of thinking-aloud or any other introspective method.

II. To obtain mainly unedited and unanalyzed data, subjects were asked to think aloud only. In this way, I wanted to make sure that the method of data collecting exerts the least influence possible on the mental processes of task performance.

III. Thinking-aloud was also requested because it is a type of concurrent verbalization. In contrast to retrospective reports, subjects are not exposed to a memory load, which means that the information they externalize is potentially more complete.

IV. Translation processes mainly operate on verbally encoded data. This seems to be another favourable precondition for thinking-aloud to yield the largest possible amount of information on on-going mental processes.

V. In my analysis of translation processes I concentrated on translators' problems and on what they thought aloud when they found themselves confronted with such problems. There was hardly any thinking-aloud during subjects' automatic, i.e. 
largely unconscious, substitution of source-language text segments by targetlanguage text segments.

VI. Solving translation problems is often carried out as a series of steps. Generally, subjects do not immediately reach solutions which they consider to be optimal. They rather have to work out optimal solutions. In searching through their memories they activate informational networks thus producing interim solutions, and try to optimize these with regard to their expectation structures. The step-by-step nature of translational problem-solving is a further favourable precondition for thinkingaloud to yield many reliable data on the on-going mental processes.

From all these considerations, it becomes clear that verbal report data are useful for making hypotheses about mental processes if we take into account the conditions under which the data are externalized, and their inherent limitations.

\section{Methods for Data Analysis and Evaluation}

The analysis and evaluation of data is carried out by means of an interpretive approach, as this is customary in performance analysis. The primary aim of this approach is the hypothetical reconstruction of sense relations. The analyst interprets the collected data with regard to his/her epistemological interest and hypothetical assumptions. In the process of interpretive reconstruction, certain data are interpreted as (observable) indicators of (unobservable, mental) translation strategies. These indicators represent the basis for the formation of hypotheses on the mental translation process. - A more detailed description of these phenomena is contained in Lörscher 1991: 56ff.

The process of knowledge accumulation with respect to translation strategies has a dialectical nature. On the one hand, the analyst must have some knowledge of the concept of translation strategy in order to be able to ascribe the status of strategy indicators to certain signs. On the other hand, it is only by their indicators that translation strategies are constituted, so that knowledge of them can, to a very large extent, only be gained by means of strategy indicators. Therefore, the analyst must often proceed in a speculative and hypothetical way. $\mathrm{S} /$ he often does not interpret certain signs to be indicators as a result of his/her knowledge of the respective entity or of the relationship between an indicator and a segment of reality, but rather on the basis of considerations of probability. They can be corroborated or turn out to be false in the course of accumulating further knowledge of the phenomena and of gathering more experience in intepretation. The analyst of the translations, which are explicitly monological texts is possibly in a less favourable position than somebody who has to interpret (dialogical) conversations. In conversations, the communication partners negotiate reality and jointly constitute sense (Mehan/Wood 1975; Psathas 1972). This often manifests itself in the text produced and thus becomes accessible to analysis. In (explicitly) monological texts, however, the text producer implies his / her model of reality and does not usually make it explicit. The same probably applies to sense constitution. It is likely to be verbalized to a lesser degree in monologues than in conversations. In order to compensate for these deficiencies, at least partially, the method of thinking-aloud suggests itself. By means of this procedure it is possible to obtain information which is generally made explicit in (dialogical) conversations but which is implicit in (monological) texts.

\section{A STRATEGIC ANALYSIS OF THE TRANSLATION PROCESS}

Translation strategies have been defined by me as procedures which the subjects employ in order to solve translation problems (Lörscher 1991: 76ff.). Accordingly, translation strategies have their starting-point in the realization of a problem by a subject, and 
their termination in a (possibly preliminary) solution to the problem or in the subject's realization of the insolubility of the problem at the given point in time.

Between the realization of a translation problem and the realization of its solution or insolubility, further verbal and/or mental activities can occur which can be interpreted as being strategy steps or elements of translation strategies. They can be formalized to yield categories of a model for the strategic analysis of the translation process. The model consists of three hierarchical levels. The first and lowest contains those phenomena which can be interpreted to be elements of translation strategies, i.e. the smallest detectable problem-solving steps. The second level captures the manifestations of translation strategies, and the third and highest level comprises the translation versions. A detailed description of the model can be found in Lörscher 1991: 92ff.

\section{Elements of Translation Strategies}

Elements of translation strategies can be distinguished as to whether they are original or potential. The former exclusively occur within strategic phases of the translation process and are thus original elements of translation strategies. The latter also occur within non-strategic phases of the translation process. The 22 elements of translation strategies which could be found in my data corpus are listed below.

Original Elements of Translation Strategies

\begin{tabular}{|c|c|}
\hline RP & : Realizing a Translational Problem \\
\hline VP & : Verbalizing a Translational Problem \\
\hline$\rightarrow S P$ & $\begin{array}{l}\text { Search for a (possibly preliminary) Solution to a Translational } \\
\text { Problem }\end{array}$ \\
\hline SP & : Solution to a Translational Problem \\
\hline PSP & : Preliminary Solution to a Translational Problem \\
\hline $\mathrm{SPa}, \mathrm{b}$ & : Parts of a Solution to a Translational Problem \\
\hline SPØ & : A Solution to a Translational Problem is still to be found $(\varnothing)$ \\
\hline $\mathrm{SP}=\varnothing$ & : Negative $(\varnothing)$ Solution to a Translational Problem \\
\hline PSL & Problem in the Reception of the SL Text \\
\hline
\end{tabular}

Potential Elements of Translation Strategies

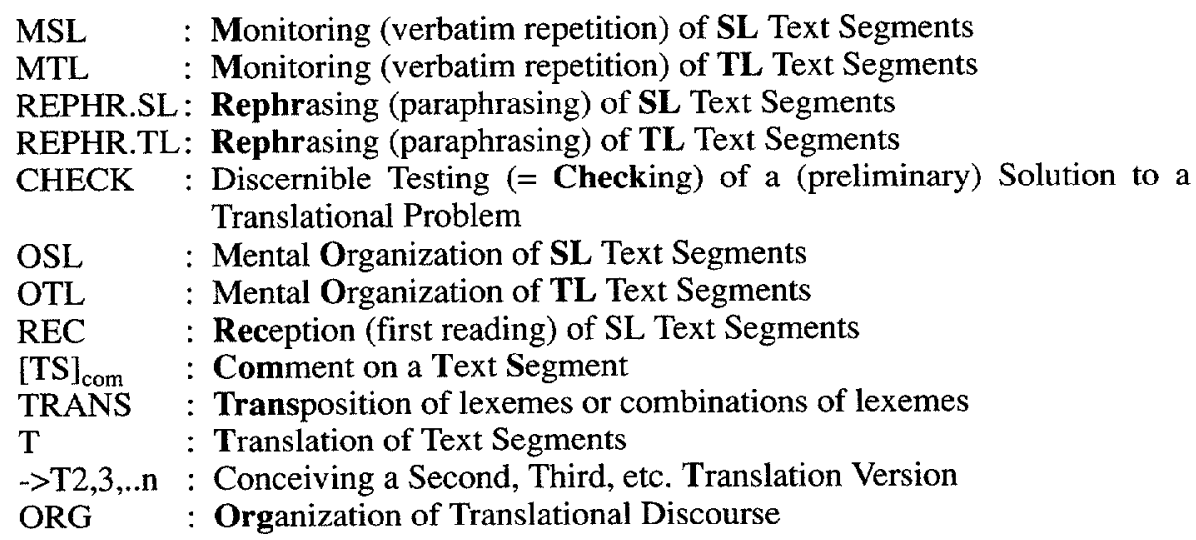

\section{Translation Strategies}

Translation strategies are procedures for solving translation problems. They are constituted by those minimal problem-solving steps I have just outlined. As the data 
show, the elements of translation strategies combine in specific ways only to build up structures. Accordingly, translation strategies contain one or more of these structures.

Following a model for the analysis of discourse, which I developed in a different context (Lörscher 1983), a distinction is made between basic structures, expanded structures, and complex structures of translation strategies. This is based on the fact that although translation strategies can be highly complex and thus difficult to document and describe in their manifold forms, they can be reduced to a fairly small number of simpler structures. The application of a generative principle allows the transformation of basic structures into expanded and complex structures.

As regards their description, basic structures are the simplest structural types. This, however, does not necessarily imply that in the course of the translation the subjects consider those problems which they address with strategies consisting of one basic structure only to be especially easy to solve. As a consequence, the linguistic complexity of the analytical constructs need by no means be identical with the psychological complexity of the problems, as assessed by the subjects. It can be assumed, however, that, in retrospect, the subjects consider those problems to be especially complex, and thus difficult to solve, which they have tackled with linguistically complex strategies requiring a great amount of time and mental effort.

In my data corpus, a tendency seems to be recognizable according to which the subjects generally use (linguistically) simple strategies first, and only when they turn out to be unsuccessful do the subjects employ more complex strategies. This procedure of the subjects complies with the generative principle whereby complex translation strategies are constituted by and can be derived from simpler structures.

The types of translation strategies used by the subjects of my investigations are schematically represented below.

\section{Translation Strategies}

Five types of basic structures occur in my data corpus:

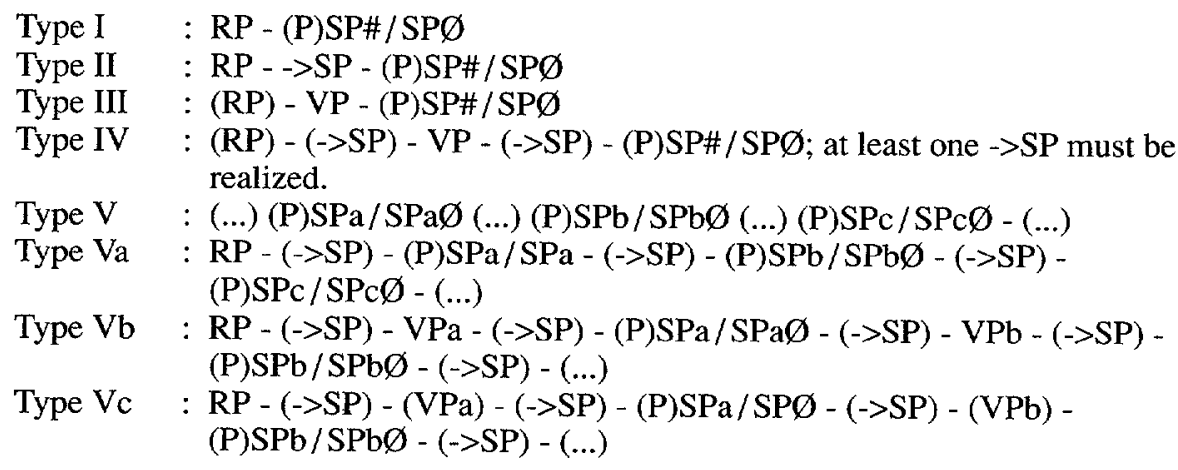

According to the generative principle, types II to IV can be derived from type I. Type II contains an additional phase of searching for a solution ( $>$ SP), type III contains an additional verbalization of the translational problem (VP), and type IV contains both an additional phase of searching $(\rightarrow \mathrm{SP})$ and a verbalization (VP).

Expanded structures of translation strategies consist of a basic structure which contains one or more expansions. Expansions are defined as additional elements of a strategy itself. So, for example, the strategy RP - VP - $>$ SP - VP2 - > SP - PSP contains a type IV structure, i.e. RP - (->SP) - VP - (->SP) - (P)SP, with two additional elements of the structure itself, (VP2, $->\mathrm{SP})$, i.e. with two expansions. 
Complex Structures are built up of several basic and/or expanded structures. An example may elucidate this. The strategy VP - SP $\emptyset$ - $>$ SP - PSP contains a type III and a type II structure. The former is terminated by SPØ, i.e. with the subject leaving the problem aside in order to try and solve it later. The second part of the strategy is the realization of a type II structure. It terminates with a preliminary solution to the translation problem.

The translation strategies, which I have just described, can be represented in the following flow chart:

\section{Flow Chart of Strategic Tranlating}

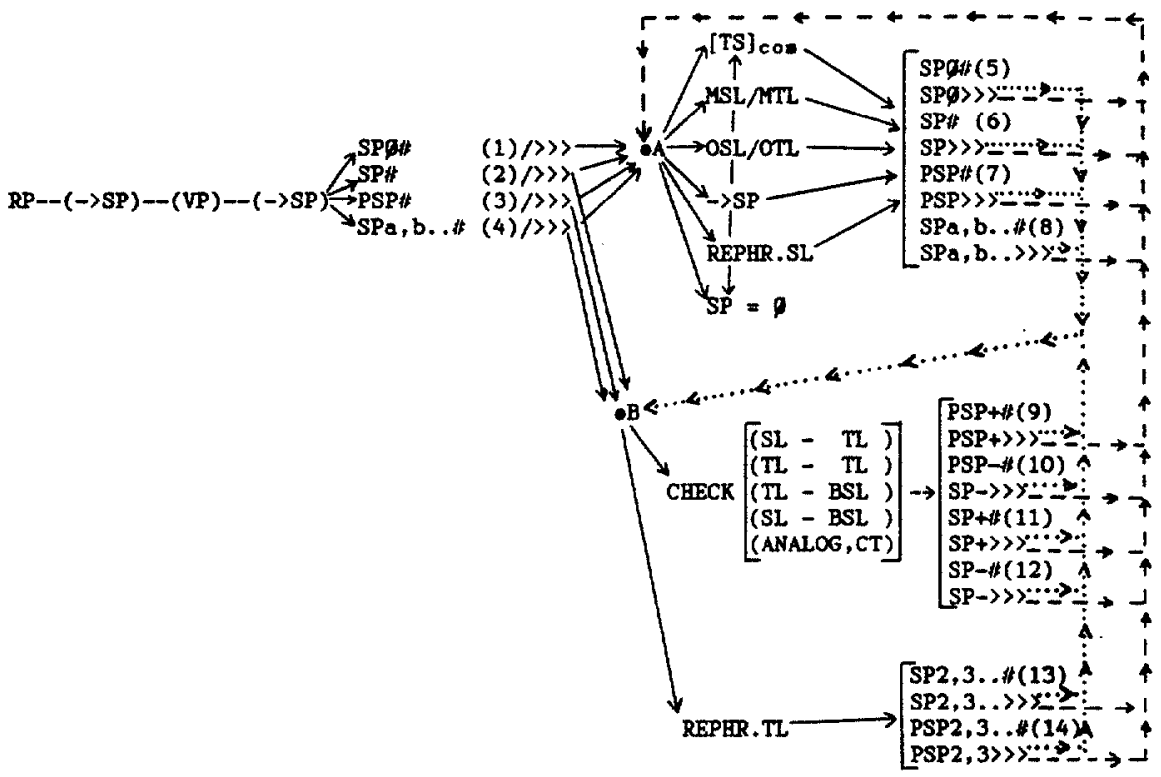

$\gg>$ = continuation symbol denoting continuation of strategy; \# $\Rightarrow$ termination
symbol denoting termination of strategy; elements in brackets () are optionsymbol denoting termination of strat

\section{Explanatory Remarks to the Flow Chart of Strategic Translating}

After realizing (RP) and possibly verbalizing (VP) a translational problem, and after a potential search for a solution ( $\rightarrow$ SP), a subject may achieve a solution (SP, SPa,b..) or a preliminary solution (PSP) immediately (2), (3), (4), in which cases the problem-solving process may come to an end (\#). This may also be the case when the subject considers a problem insoluble (1).

Having found a (preliminary) solution (2), (3), (4), the subject may go on dealing with the problem $(\gg>)$ and proceed to either decision node $A$ or $B(\cdot A, \cdot B)$. When the subject cannot find a solution (SPØ), $s /$ he can only proceed to decision node $A$. Having reached decision node A, the subject may try to bring about a solution by monitoring SL or TL text segments (MSL, MTL), and/or by rephrasing SL text segments (REPHR.SL), and/or by (further) searching for a solution (->SP), and/or by mentally organizing SL or TL text segments (OSL, OTL), and/or by commenting on text segments ([TS $]_{\text {com }}$ ), and /or by conceiving a negative solution $(S P=\varnothing)$. 
As a result of these problem-solving activities, the subject may either find a (preliminary) solution to the problem (PSP, SP, SPa,b..) or not (SPØ). Here again, the problem-solving process may come to a successful (6), (7), (8) or to an unsuccessful (5) end.

When the subject decides to continue, $\mathrm{s} /$ he may either go back to decision node $\mathrm{A}$, which is possible after SP $\varnothing$, PSP, SP, and SPa,b..; or s/he may proceed to decision node $\mathrm{B}$, which, however, is not possible after SPØ.

Having reached decision node $B$, the subject continues by rephrasing (REPHR.TL) the respective TL text segment (SP, PSP, SPa,b..) or by testing it (CHECK).

The result of the rephrasing is a new (preliminary) solution ((P)SP2,3.., SPa2,3.., $\mathrm{SPb} 2,3 \ldots$...). Here again, the problem-solving process may come to an end, as in (13) and (14), or the subject may proceed to one of the decision nodes again.

After the testing of a TL text segment, the (preliminary) solution may either be corroborated $((\mathrm{P}) \mathrm{SP}+)$ or rejected $((\mathrm{P}) \mathrm{SP}-)$. In both these cases, the subject may terminate the problem-solving process (9), (10), (11), (12) or proceed to either decision node A or B.

\section{Translation Versions}

As my data clearly show, the translation process contains both strategic phases, which are directed towards solving translational problems, and non-strategic phases, which aim at accomplishing tasks. The former range from the realization of a translational problem to its solution or to the realization of its insolubility at a given point in time. The latter start with the extraction of a unit of translation and terminate when it has been (preliminarily) rendered into TL or when a translational problem arises. Translation versions are derived from a maxim which dominates an entire translation and according to which a translation should not merely convey the sense of the SL text into TL, but should be an adequate piece of discourse produced according to the TL norms of language use.

Whereas translation strategies can, by definition, only occur within strategic phases of the translation process, translation versions can consist of strategic and/or nonstrategic components. They can be located within strategies (i.e. intrastrategic versions), between strategies, and can range from one into another strategy. The latter case is called intraversional strategy.

As my data reveal, the subjects often produce several translation versions. They can comprise the entire text or only parts of it (e.g. paragraphs, sentences, clauses, or phrases). The production of several translation versions can have various reasons, of which at least four can be interpreted from the data:

i. If a subject does not succeed in solving a translational problem at the first attempt, $\mathrm{s} /$ he may try to solve the problem in its further context. This may require a second, third, etc. translation version which potentially also contains non-strategic parts of the translation.

ii. If, at the first attempt, a subject does not succeed in rendering a strategic or nonstrategic part of an SL text into TL in a way which is considered adequate, the subject may try to optimize the TL text production by conceiving a more adequate second, third, etc. translation version.

iii. If a subject, while checking a complex TL text segment, finds an alternative for it, $\mathrm{s} /$ he may conceive a further translation version which contains the alternative TL text segment plus part of its context.

iv. If a subject translates a complex SL text segment consisting of several strategic and/or non-strategic parts by successively rendering its components into TL, the subject may produce a further version of the TL text segment. Thus, s/he may become aware of the complex interrelationships between the components of the TL text segment. $\mathrm{S} / \mathrm{he}$ may realize that the components, in order to make an adequate 
stretch of TL discourse, cannot be put together in the same way as they were successively translated from the SL.

APPLICATION OF THE MODEL OF ANALYSIS

The model for the strategic analysis of the translation process which $I$ have outlined will now be exemplified by applying it to a segment of a translation of my data corpus. The analyses are reproduced in detail and commented on on the following pages.

\begin{tabular}{|c|c|c|c|c|}
\hline No. & $\begin{array}{l}\text { T4 S28 } \\
\text { Text }\end{array}$ & $\begin{array}{l}\text { Categories } \\
\text { of Analysis }\end{array}$ & & Comments \\
\hline $\begin{array}{l}1 \\
2\end{array}$ & $\begin{array}{l}\text { Okay, ich les mir den Text } \\
\text { erst mal durch }\end{array}$ & ORG & & $\begin{array}{l}\text { The subject organizes } \\
\text { (initiates) the discourse. }\end{array}$ \\
\hline 3 & (Reads text aloud) & REC & & $\begin{array}{l}\text { The first reading of the text } \\
\text { is categorized as REC. }\end{array}$ \\
\hline 4 & (2s) Okay. & ORG & & $\begin{array}{l}\text { This organizing utterance marks } \\
\text { the beginning of the translation. }\end{array}$ \\
\hline 5 & Sale of Honours & OSL & & $\begin{array}{l}\text { The first unit of translation } \\
\text { is determined. }\end{array}$ \\
\hline 6 & $(2 s)$ & RP & & $\begin{array}{l}\text { The subject realizes a translational } \\
\text { problem. }\end{array}$ \\
\hline 7 & vielleicht 'Ausverkauf & $\mathrm{PSPa}-$ & $\mathbf{S}$ & $\begin{array}{l}\text { The subject verbalizes } \\
\text { the first part of a possible } \\
\text { solution. }\end{array}$ \\
\hline 8 & $(2 s)$ & $\rightarrow$ SP & I & $\begin{array}{l}\text { The remaining part of the solution is } \\
\text { searched for. }\end{array}$ \\
\hline 9 & ehm Ehrentiteln' & $\mathrm{PSPb}=$ & & $\begin{array}{l}\text { The remaining part of the solution } \\
\text { is verbalized. }\end{array}$ \\
\hline 10 & $(3 \mathrm{~s})$ & $\begin{array}{l}\text { CHECK } \\
(7,9)+=\end{array}$ & & $\begin{array}{l}\text { During this pause, the subject probably } \\
\text { checks the two parts of the solution. As } \\
\text { the translation proceeds, the result of } \\
\text { the checking is probably a corrobora- } \\
\text { tion of the utterances } 7 \text { and } 9 .\end{array}$ \\
\hline
\end{tabular}

11 'There is no possible argument

12 (2s) on which the decision by

13 the congregation of

REC

Reading is categorized as REC

14 Oxford University to

15 refuse Mrs Thatcher the proposed honorary

16 degree is worthy of respect.'

\begin{tabular}{|c|c|c|c|c|}
\hline 17 & (4s) ehm (3s) & $\mathrm{RP} /->\mathrm{SP}=$ & & $\begin{array}{l}\text { The subject realizes a problem and } \\
\text { starts searching for a solution. }\end{array}$ \\
\hline 18 & $\begin{array}{l}\text { Es gibt keinen (1s) } \\
\text { Grund }\end{array}$ & SP & $\begin{array}{l}\mathbf{S} \\
2\end{array}$ & $\begin{array}{l}\text { A solution to the } \\
\text { translational problem is found. }\end{array}$ \\
\hline 19 & $(7 \mathrm{~s})$ & CHE & & $\begin{array}{l}\text { Here, the subject probably tests } \\
\text { the preceding TL text segment. }\end{array}$ \\
\hline
\end{tabular}




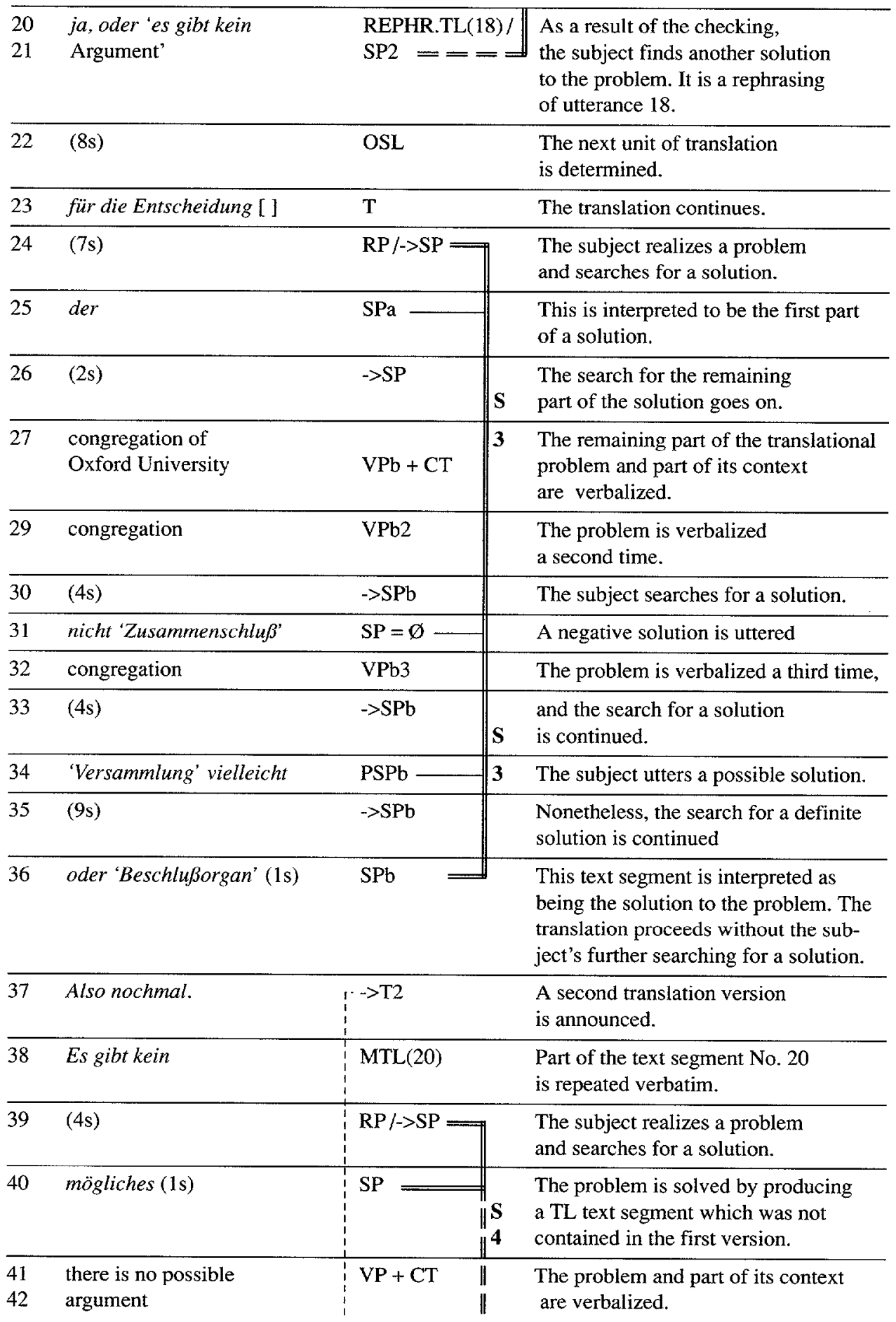




\begin{tabular}{ll|ll}
\hline 43 & (11s) & CHECK(40) & The solution uttered in No. 40 is tested. \\
\hline 44 & $\begin{array}{l}\text { irgendwas mit } \\
\text { wie auch immer' }\end{array}$ & REPHR.TL(40) & $\begin{array}{l}\text { As a result of the checking, the subject } \\
\text { finds another solution to the problem. }\end{array}$ \\
\hline 46 & Es gibt kein & It is a rephrasing of No. 40.
\end{tabular}

$(\mathrm{xs})=$ pause of $\mathrm{x}$ seconds; $==$ translation strategy; $-\cdots=$ translation version.

The transcribed and analyzed translation segment contains four strategies the types of which can be found below:

S1 : Nos. 6-9/10

This strategy realizes a type Va basic structure. It is followed by CHECK + . At the end of the strategy, a solution to the translational problem is found.

Type: Va + CHECK + SP\#

S2: Nos. $17-18 / 21$

Strategy 2 is the realization of a type II basic structure with two bound elements, CHECK and REPHR.TL.

Type: II + CHECK + REPHR.TL SP\#

S3 : Nos. $24-36$

This strategy is based on a complex structure consisting of an expanded and a basic structure. The expanded structure belongs to type $\mathrm{Vc}$ and contains three expansions $(2 \mathrm{VP},->\mathrm{SP})$ and one embedded element $\langle\mathrm{SPb}=\emptyset\rangle$. As a result of the expanded structure, $\mathrm{PSPb}$ is found. The second part of the strategy is a basic structure of the type II. SPb and thus an entire solution to the problem is found.

Type: $\mathrm{Vc}+3 \mathrm{BEX}+<\mathrm{SPb}=\emptyset>-$ II SP\# 
S4: Nos. 39-40/45

This is an intraversional strategy realizing a type II basic structure. Three bound elements are appended to it: VP+CT, CHECK, and REPHR.TL.

Type: II' + VP + CT + CHECK + REPIIR.TL SP\#

\section{A QUANTITATIVE ANALYSIS OF THE TRANSLATION STRATEGIES}

The qualitative analysis of my data corpus has yielded a differentiation of types of strategies with different internal structures. In this section of my paper, an outline of a quantitative analysis of the different translation strategies will be given in order to gain insights into the frequency and distribution of the strategies in the entire corpus and in the translations from and into the mother tongue. The data corpus for this investigation comprises forty-five translations from and into English produced by advanced learners of English as a foreign language.

\section{Basic, Expanded, and Complex Structures}

As pointed out in the preceding section, translation strategies can occur as basic, expanded, and complex structures. According to a generative principle, complex structures are built up of several basic and/or expanded structures. The frequency of occurrence of these structures, both in numerical values and percentages, is recorded in the following diagram:

\section{Basic, Expanded, and Complex Structures in the Translations from and into the Mother Tongue}

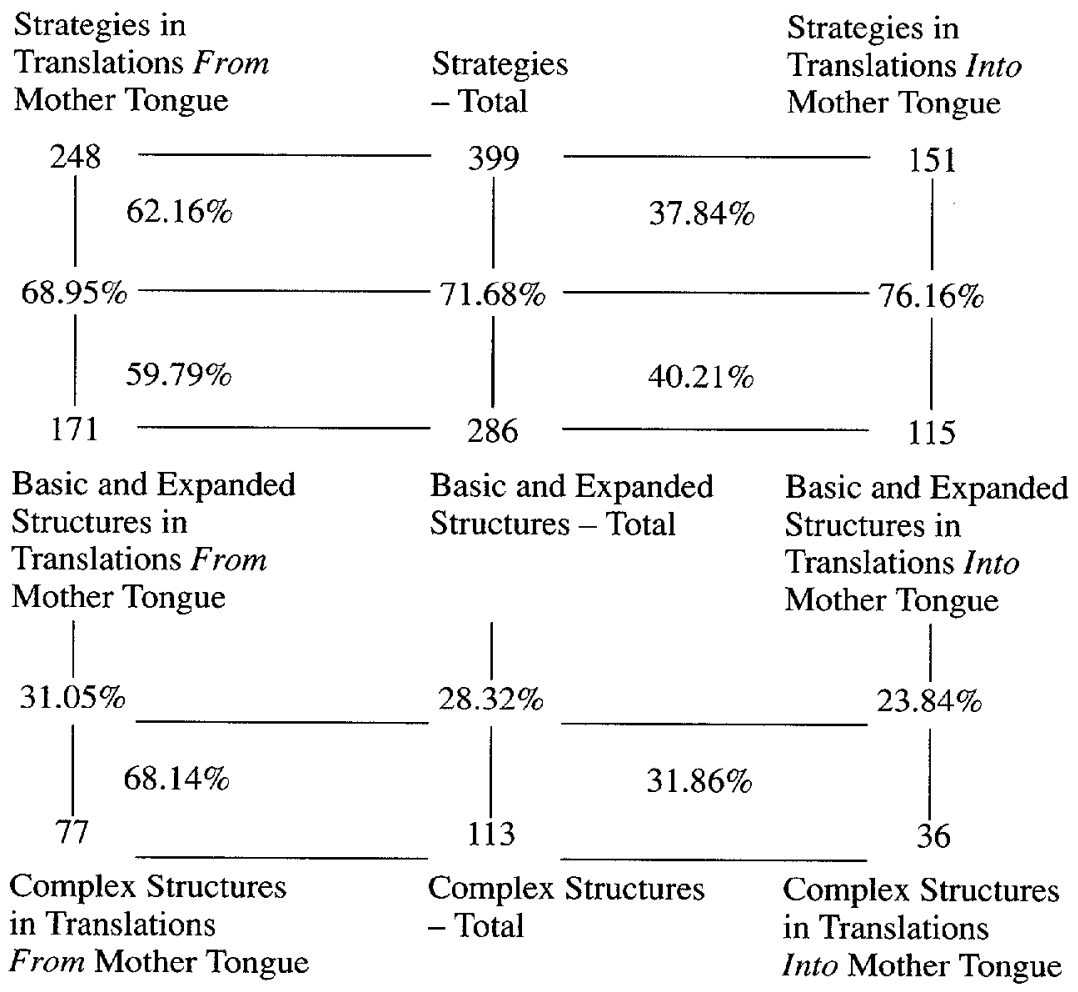


The forty-five translations which constitute the corpus of investigation contain 399 strategies altogether. $248(=62 \%)$ of them occur in the translations from the mother tongue, and $151(=38 \%)$ occur in the translations into the mother tongue. In other words, each of the twenty-five translations from the mother tongue contains an average of ten, and each of the translations into the mother tongue contains an average of eight translation strategies.

Of the 399 strategies documented, 286 are basic or expanded structures. This is surprising in so far as the subjects employed linguistically simple strategies in about $70 \%$ of the cases to solve the problems they were faced with during the translations, and only in about $30 \%$ of the cases did they use linguistically complex strategies. However, what was pointed out in the preceding section, must be taken into consideration, i.e. the fact that linguistically simple strategies need not necessarily be regarded as simple and linguistically complex strategies as complex by the subjects during the translations.

The distribution and the percentages of the basic and expanded structures on the one hand, and of the complex structures on the other yield a further important insight into the translation process. As has already been pointed out, basic and expanded structures constitute complex structures. Therefore, a basic or expanded structure followed by at least one more basic or expanded structure must be produced so that a complex structure can be constituted. Thus, when a subject achieves a solution to a problem or realizes its insolubility by means of a basic or expanded structure, the translation strategy is terminated. As mentioned above, this applies to ca. $72 \%$ of all the translation strategies.

When a subject cannot bring about a solution to a translation problem by means of a simple or expanded structure but continues his/her problem-solving activities and produces (a) further basic or expanded structure(s), a complex structure is thus constituted. Therefore, the assumption suggests itself that the high percentage of basic and expanded structures in the corpus indicates the fact that the subjects can either solve the great majority of the problems they face or realize their insolubility after having made a comparatively low strategic effort. Only relatively few translation problems require a high strategic effort before they can be solved or their insolubility be realized.

Of the 286 basic and expanded structures of the corpus, 171 occur in the translations from the mother tongue and 115 in the translations into the mother tongue. In other words, about $69 \%$ of all the strategies contained in the translations from the mother tongue and about $76 \%$ of all the strategies contained in the translations into the mother tongue realize basic or expanded structures. As shown in the diagram, the percentage of basic and expanded structures in the translations into the mother tongue is about $7 \%$ higher than the percentage of these structures in the translations from the mother tongue. If one additionally takes into account the fact that the translations into the mother tongue contain an average of eight and the translations from the mother tongue an average of ten strategies, the assumption seems justified that the effort which the subjects must make to solve the problems of the translations into the mother tongue is slightly lower than for the problems in the translations from the mother tongue.

Further-reaching conclusions about the translations from and into the mother tongue, in general, would be of a purely speculative kind.

Types of Basic- and Expanded Structures follows:

The basic and expanded structures are distributed over the five structural types as

Type I : RP - (P)SP\#; 18 times (= 4.51\% of all the strategies)

In the translations from the mother tongue, this structural type occurs 6 times $(=2.42 \%)$, and the translations into the mother tongue contain 12 type I basic structures $(=7.95 \%)$. 
It can be assumed that the translation problems which are solved by means of these strategies are retrieval problems. By putting the problematic SL item into the focus of cognitive attention, the subject may succeed in making the equivalent TL element accessible to him or her. As concerns the direction of the translations, it can be observed that type I structures occur about three times more frequently in the translations into the mother tongue than in the translations from the mother tongue.

Thus it is justified to conclude that the subjects succeed better and more frequently in retrieving and making accessible to them items of their mother tongue than items of a foreign language.

Type II : RP - ->SP - (P)SP\#; 106 times (= 26.57\% of all the strategies)

In the translations from the mother tongue, this type occurs 56 times, which amounts to $22.58 \%$ of all the respective strategies.

The translations into the mother tongue contain 50 structures of this type, which corresponds to $33.11 \%$ of all the strategies in the translations into the mother tongue. Translation problems which are addressed by type II strategies are partly retrieval problems for lexeme equivalents and partly problems for whose solution processes of construction or of syntactic or semantic paraphrasing are required.

Type III : (RP) - VP - (P)SP\#; 15 times (= 3.76\% of all the strategies)

In the translations from the mother tongue, this type occurs 10 times, which corresponds to $4.03 \%$. In the translations into the mother tongue, this type occurs 5 times $(=3.31 \%)$.

With a percentage of less than 4 , this is the least frequently occurring type of structure. It differs from type I only by an additional verbalization of the respective problem. When a subject does not succeed in finding a TL equivalent to an SL item solely by putting the problematic item into his/her focus of attention, the subject can verbalize the SL item as a specific problem-solving activity. The verbalization results in a (further) mental focussing on the problem.

Type IV : ((RP) - (->SP)) - VP - (->SP) - (P)SP\#; 61 times (= 15.29\% of

all the strategies)

In the translations from the mother tongue, this type occurs 38 times, which corresponds to $15.32 \%$. In the translations into the mother tongue, 23 type IV structures $(=15.23 \%)$ are contained.

When a subject does not succeed in finding a TL equivalent to an SL item solely by putting the problematic item into his/her focus of attention, specific problemsolving activities can follow. The subject can initiate a phase of searching for a solution (as in type II), or $\mathrm{s} /$ he can verbalize the problematic SL text segment. If both these strategic measures turn out to be unsuccessful, a further focussing on the problem can occur. In the case of type II, the phase of searching is followed by a verbalization of the problem and perhaps a further phase of searching for a solution. In the case of type III, the verbalization is followed by a phase of searching. Thus, type IV structures can be regarded as continuations of type II or type III structures. This is why they bring together the structural characteristics of these two types.

Type V : a. RP - (->SP) - (P)SPa - (->SP) - (P)SPb ...\#; 41 times

$(=10.28 \%$ of all strategies $)$

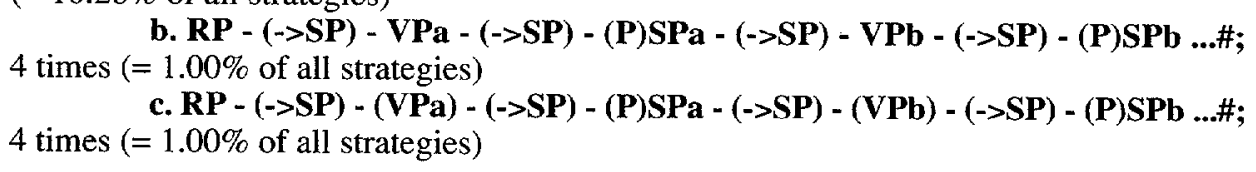


Types $\mathrm{V}$ occur 37 times $(=14.92 \%)$ in the translations from the mother tongue and 12 times $(=7.95 \%)$ in the translations into the mother tongue.

Type V strategies are mainly used to solve complex problems if these can be split up into parts and solved successively.

Both the lexico-syntactic and the purely syntactic problems reveal a high degree of complexity and require mainly constructive procedures for their solution. Obviously, the problematic text segments do not function as units of translation. They are too large and/or too complex to be processed in one go. Rather, they are split into parts which can be handled by the processing system, successively transferred into TL and then joined together again.

\section{Strategies for Translation into and from the Mother Tongue: A Summarizing Comparison}

To conclude this paper, I would like to briefly compare the strategies which my subjects used when translating from and into the mother tongue.

In spite of many differences, the abundance of individual results which the quantitative analysis of my data has yielded can be said to coalesce into quite a homogeneous picture. The results of the respective analyses show that the subjects generally attempt to solve problems in the translations into the mother tongue by means of linguistically less complex strategies than problems in the translations from the mother tongue. Possibly, they estimate the former problems to be less serious than the latter.

As the distribution of the basic and expanded structures reveals, their percentage in the translations into the mother tongue is about $7 \%$ above that in the translations from the mother tongue. Apparently, problems in the translations into the mother tongue are less difficult and laborious to solve than problems in the translations from the mother tongue. The reverse distribution is true for the complex structures. The assumption made is also supported by the distribution of the types of basic structures. The less complex types I and II occur more frequently in the translations into the mother tongue, whereas the more complex type $\mathrm{V}$ can be found twice more frequently in the translations from the mother tongue.

On balance, the result of this section can be summarized as follows: Although differences between the strategies of the translations into and from the mother tongue exist, these differences are of degree, and not of kind. They are partly caused by the different distributions of the types of problems and by the different degrees of difficulty of the respective problems.

\section{BIBLIOGRAPHY}

BÜHL, W. L. (Ed.) (1972): Verstehende Soziologie - Grundzüge und Entwicklungstendenzen, München. ERICSSON, K.A. and SIMON, H.A. (1984): Protocol Analysis, Verbal Reports as Data, Cambridge /MA. GERLOFF, P.A. (1988): From French to English: A Look at the Translation Process in Students, Bilinguals, and Professional Translators, Mimeo, Harvard University.

JÄÄSKELÄINEN, R.H. (1990): Features of Successful Translation Processes: A Think-Aloud Protocol Study, Mimeo, University of Joensuu, Savonlinna School of Translation Studies.

KRINGS, H.P. (1986): Was in den Köpfen von Übersetzern vorgeht, Eine empirische Untersuchung der Struktur des Übersetzungsprozesses an fortgeschrittenen Französischlernern, Tübingen.

LÖRSCHER, W. (1983): Linguistische Beschreibung und Analyse von Fremdsprachenunterricht als Diskurs, Tübingen.

LÖRSCHER, W. (1991): Translation Performance, Translation Process, and Translation Strategies. A Psycholinguistic Investigation, Tübingen.

LÖRSCHER, W. (in preparation): Translation as Process. An Empirical Investigation into the Translation Process of Professionals, Bilinguals, and Foreign Language Learners.

MEHAN, H. and WOOD, H. (1975): The Reality of Ethnomethodology, New York.

PSATHAS, G. (1972): "Verstehen, Ethnomethodologie und Phänomenologie," Bühl 1972, pp. 284-303.

SÉGUINOT, C. (Ed.) (1989): The Translation Process, Toronto.

TIRKKONEN-CONDIT, S. (Ed.) (1991): Empirical Research in Translation and Intercultural Studies, Tübingen. 